\title{
Atypical use of ALN inferior vena cava filters as protection devices prior to embolization of a large portosystemic shunt with Amplatzer Vascular Plugs and Glubran 2 cyanoacrylate glue
}

\author{
Pierre-Emmanuel Berthod ${ }^{1}$, Olivier Chevallier ${ }^{1}$, Marianne Latournerie $^{2}$, Sophie Gehin ${ }^{1}$, Nicolas Falvo ${ }^{1}$, \\ Marco Midulla ${ }^{1}$, Romaric Loffroy ${ }^{1}$ \\ ${ }^{1}$ Department of Vascular Medicine and Interventional Radiology, Center of Mini-Invasive Image-Guided Therapies, ${ }^{2}$ Department of \\ Gastroenterology and Hepatology, François-Mitterrand University Hospital, Dijon, France
}

Correspondence to: Prof. Romaric Loffroy, MD, PhD. Department of Vascular Medicine and Interventional Radiology, Center of Mini-Invasive ImageGuided Therapies, François-Mitterrand University Hospital, 14 Rue Paul Gaffarel, BP 77908, 21079 Dijon Cedex, France.

Email: romaric.loffroy@chu-dijon.fr.

Submitted Dec 17, 2017. Accepted for publication Mar 23, 2018.

doi: 10.21037/qims.2018.03.11

View this article at: http://dx.doi.org/10.21037/qims.2018.03.11

Spontaneous portosystemic shunts usually develop as a result of portal hypertension caused by liver cirrhosis, and may subsequently lead to hepatic encephalopathy $(1,2)$. In cases of severe portal hypertension, a part of the portal blood may reverse direction and pass through the portosystemic anastomoses into the systemic venous system. As a consequence, a variety of hepatofugal collateral vessels can develop. Porto-renal shunts are frequent portosystemic collateral pathways between the portal vein and the left renal vein that can lead to hepatic encephalopathy $(3,4)$. Vascular shunt occlusion has been described in patients with spontaneous hepatic encephalopathy, in whom transjugular intrahepatic portosystemic shunt (TIPS) is contraindicated (4-9). However, embolization of these shunt vessels may be particularly difficult for two main reasons. First, when these vessels are large, $>20 \mathrm{~mm}$ in diameter, no embolic material can be safely placed and blocked into the vessel. Second, circulation into the shunt often reverses direction and pass into the systemic venous system, leading to challenging deposit of embolic agents. The present report describes an example of atypical endovascular treatment of a large high-flow porto-renal venous shunt using ALN filters as protection devices at first, and then a combination of Amplatzer Vascular Plugs (AVP) and Glubran2 cyanoacrylate glue to totally occlude the shunt. To our knowledge, there is no mention in the literature regarding this combination of embolic materials for embolization of a portosystemic shunt affecting the left renal vein.

A 73-year-old man was admitted to the emergency department for consciousness troubles. He was known for a past history of alcoholic cirrhosis and had already been hospitalized for many episodes of variceal bleeding. Initial cerebral computed tomography (CT) and magnetic resonance imaging (MRI) scans were normal. The diagnosis of metabolic coma was suggested and the patient was transferred to the resuscitation department. The first biological results quickly confirmed this hypothesis, because of a very high blood ammonia level at $193 \mu \mathrm{mol} / \mathrm{L}$. However, this hepatic encephalopathy was relatively isolated, without other signs of liver failure, which is not typical. After many days of encephalopathy, an abdominal CT scan was performed, confirming the cirrhotic liver. The portal vein was thin, there was no splenomegaly and no ascites. The most important element was the presence of a large portosystemic shunt between the upper side of the main portal vein and the left renal vein, after a long sinuous path along the gastric lesser curvature (Figure 1). The size of this varicose vein reached $30 \mathrm{~mm}$ in diameter. It seemed to steal the majority of the portal flow, so that the size of the portal vein was only $8 \mathrm{~mm}$ in diameter wide downstream the emergence of the shunt. There was no other significant portosystemic shunt. This large and isolated shunt was considered as responsible for hepatic encephalopathy. After 


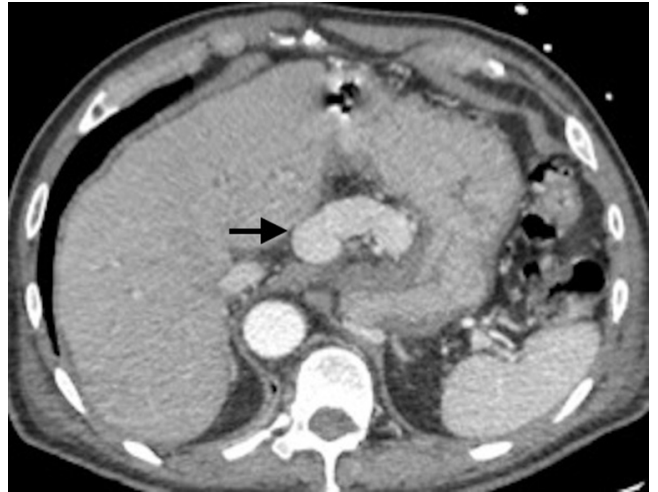

Figure 1 Contrast-enhanced abdominal CT scan shows large gastric varices with porto-renal shunt. CT, computed tomography.

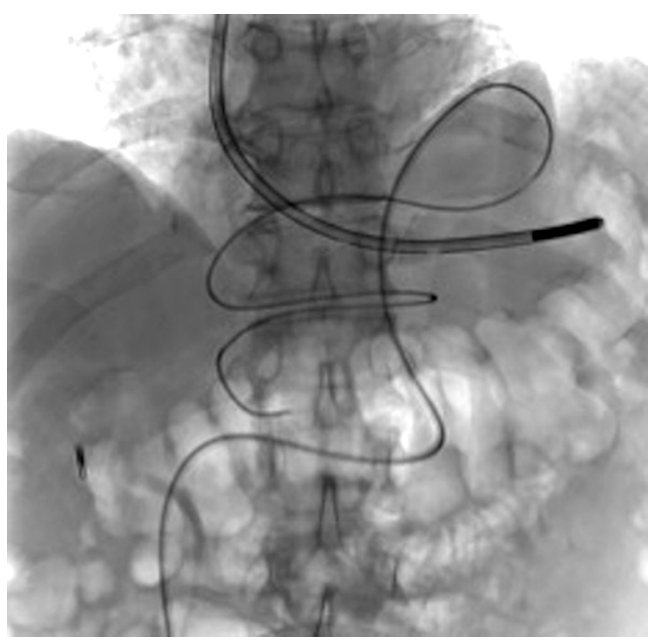

Figure 2 Catheterization of the proximal part of the shunt through the left renal vein via the inferior vena cava.

multidisciplinary meeting, embolization of this symptomatic porto-renal shunt was decided in order to decrease the blood ammonia level and reduce hepatic encephalopathy. The procedure was performed through a right femoral vein approach under local anesthesia. The left renal vein was catheterized and then the venous shunt up to the portal vein (Figures 2,3). Shunt flow was high and reversed. As the shunt was very large, the first step of the procedure consisted in the deployment of two vena cava filters (Jugular approach FJ.120096, ALN, USA) via a 7-Fr long sheath into the distal part of the shunt, just above the left renal vein, in order to facilitate closure of the varix (Figure 4). Filters then served as a scaffold and safety net for subsequent transcatheter delivery of further embolic materials. Secondly, with the

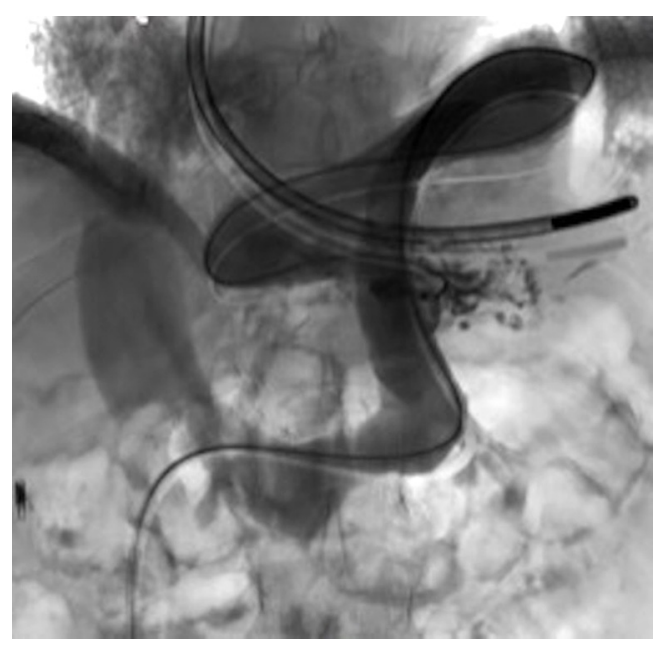

Figure 3 Angiography shows the large and long porto-renal shunt, superior to $30 \mathrm{~mm}$ in size.

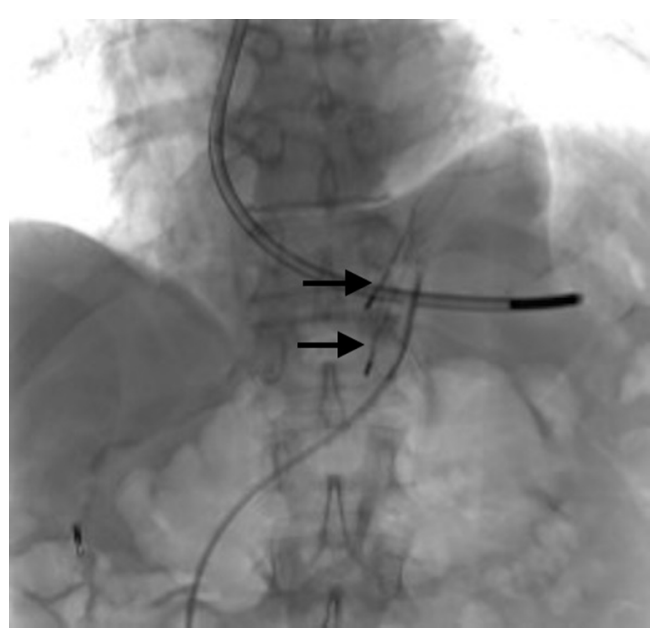

Figure 4 ALN vena cava filters deployment (arrows).

filters in place and through them, two AVPs II (St. Jude Medical, Belgium) of $22 \mathrm{~mm}$ were deployed (Figures 5,6). Their migration into the renal vein was prevented by vena cava filters. Just before vascular plugs implantation, a 2.7-Fr microcatheter (Progreat, Terumo, Japan) was coaxially placed through a 4-Fr vertebral glide catheter proximally into the shunt via a second right femoral vein sheath. Embolization of the entire shunt was then performed with $21 \mathrm{~mL}$ of a Glubran 2 glue (GEM Srl, Viareggio, Italy)/ Lipiodol oil (Guerbet, Aulnay-sous-Bois, France) mixture with a 1 to 2 ratio while removing the microcatheter up to the plugs (Figures 7,8), without any migration since flow 


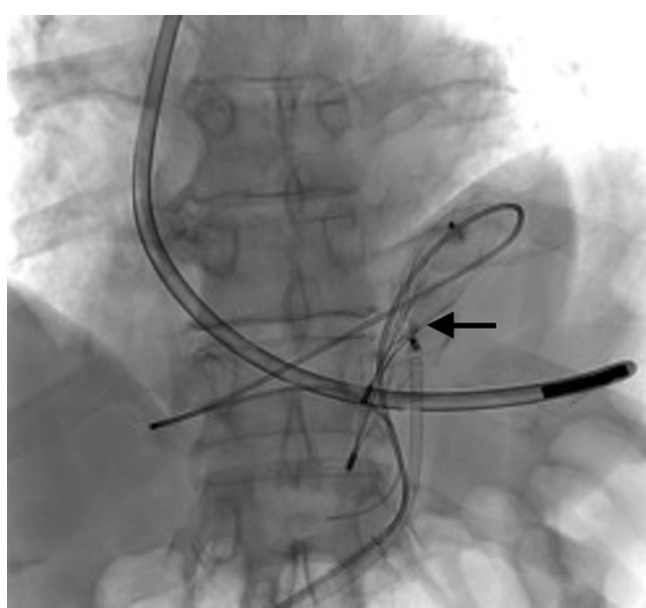

Figure 5 Deployment of the first Amplatzer Vascular Plug into the filters.

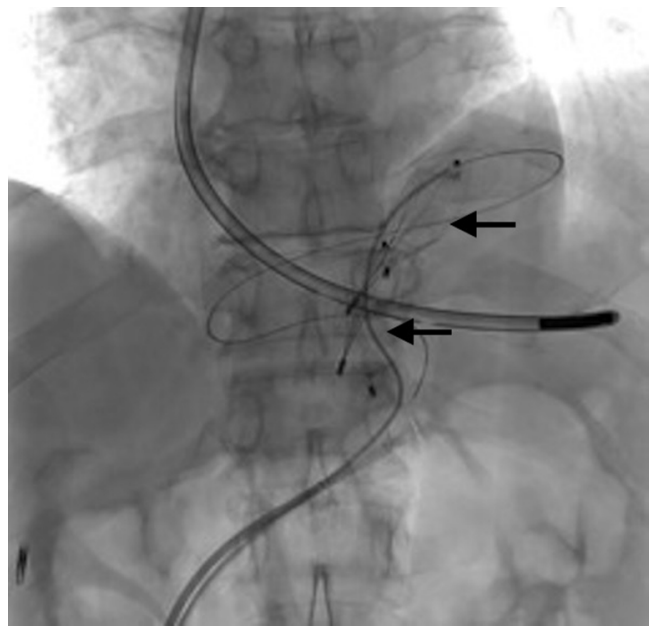

Figure 6 Second AVP deployment. AVP, Amplatzer Vascular Plugs.

was blocked by plugs. A control CT scan was performed after the procedure and confirmed complete occlusion of the shunt (Figures 9,10). Main portal vein was patent. No complication was noted. Slow but significant clinical improvement was noted within the following weeks from severe to slight hepatic encephalopathy.

Spontaneous porto-systemic shunts development is a frequent complication in cirrhotic patients with portal hypertension and may lead to hepatic encephalopathy, contraindicating TIPS placement $(1,2)$. When a large and significant shunt is detected, varix embolization may be suggested to decrease the high blood ammonia level. Some studies have reported quite good results in term of

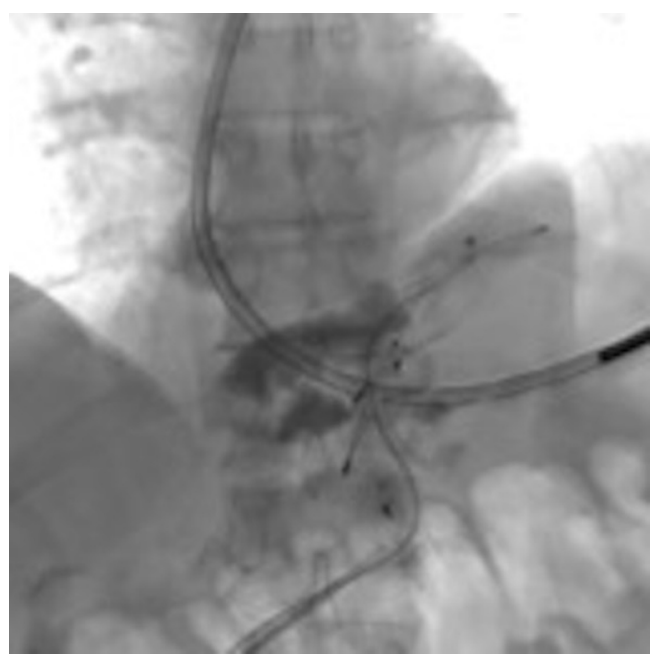

Figure 7 Glubran 2 cynaoacrylate glue/Lipiodol embolization of the proximal part of the shunt.

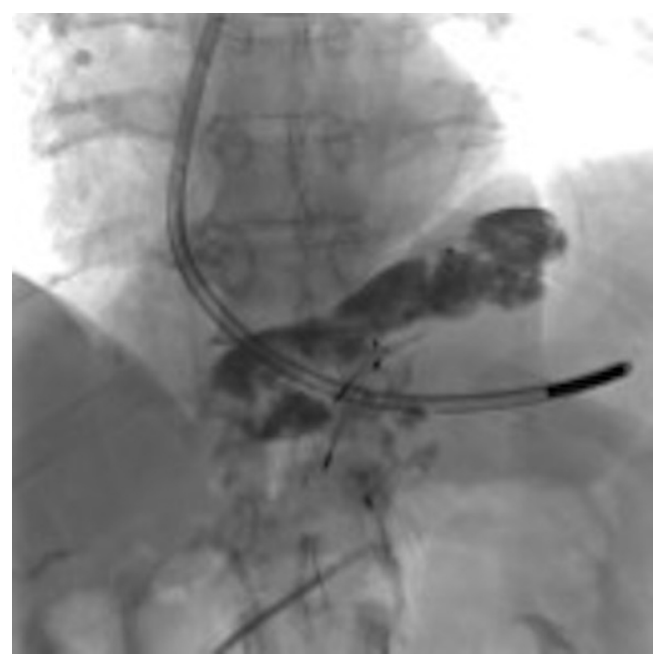

Figure 8 Glubran 2 cynaoacrylate glue/Lipiodol embolization of the distal part of the shunt up to plugs.

improvement of hepatic encephalopathy, quality of life and life expectancy after embolization of large porto-systemic shunts in case of refractory hepatic encephalopathy $(4,5)$. For other authors, endovascular occlusion gives disappointing results, especially in term of life expectancy (6), probably due to the type of patients included, with more or less severe hepatic encephalopathy.

Regarding the occlusion technique, a variety of embolic agents have been used for embolization of varices including coils, liquid sclerosants, and glues (4-9). However, 


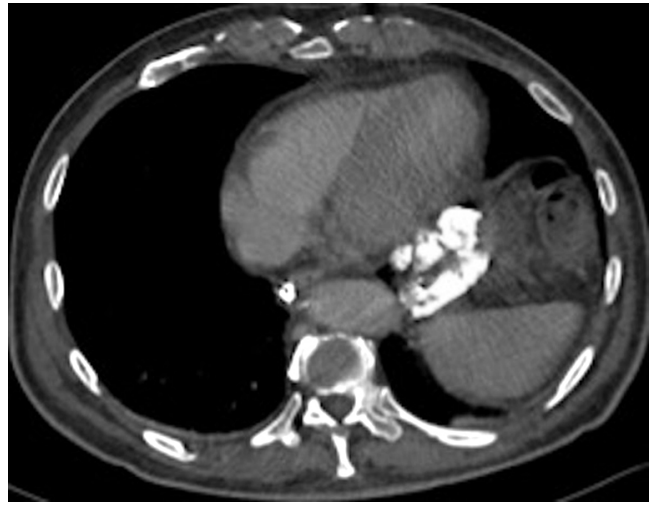

Figure 9 Control CT scan shows successful shunt glue embolization. CT, computed tomography.

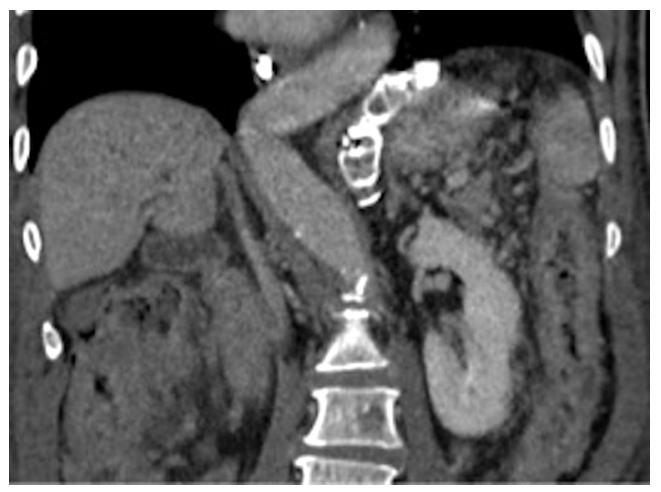

Figure 10 Coronal view of CT scan shows right placement of AVPs, without migration. AVP, Amplatzer Vascular Plugs.

embolization of large caliber vessels can be technically difficult, especially when associated with high flow, as in the present case. Available mechanical agents such as coils and plugs, even the largest ones, may be not large enough to allow compact and safe deposition. Subsequently, in order to minimize the risk of migration, we decided to first place vena cava filters into the shunt, just above the left renal vein, in order to facilitate closure of the varix with AVPs and glue. This worked successfully as no plugs migrated through the filters. Few authors have reported the use of vena cava filters acting as devices to retain embolization materials. In that case, the jugular version of the ALN filter was selected so that the apex of the filters would be directed such that the plugs could be deposited into them. Placement of the ALN filters permitted the subsequent deployment of embolization plugs easily, compactly, and without fear of plugs migration. Furthermore, cyanoacrylates were used to occlude the entire shunt more distally through the filters and plugs. Glue is particularly useful to fill in large venous shunts. It allows for fast and definitive embolization and avoid placement of uncountable coils or plugs.

In conclusion, the use of vena cava filters packed with embolization AVPs and cyanoacrylate glue provides an alternative technique for occlusion of large high-flow portosystemic shunt vessels.

\section{Acknowledgements}

None.

\section{Footnote}

Conflicts of Interest: The authors have no conflicts of interest to declare.

Informed Consent: Written informed consent was obtained from the patient for publication of this Case Report and any accompanying images.

\section{References}

1. Park SJ, Kim YK, Seo YS, Park SW, Lee HA, Kim TH, Suh SJ, Jung YK, Kim JH, An H, Yim HJ, Jang JY, Yeon JE, Byun KS. Cyanoacrylate injection versus band ligation for bleeding from cardiac varices along the lesser curvature of the stomach. Clin Mol Hepatol 2016;22:487-94.

2. Laleman W, Simon-Talero M, Maleux G, Perez M, Ameloot K, Soriano G, Villalba J, Garcia-Pagan JC, Barrufet M, Jalan R, Brookes J, Thalassinos E, Burroughs AK, Cordoba J, Nevens F; EASL-CLIF-Consortium. Embolization of large spontaneous portosystemic shunts for refractory hepatic encephalopathy: a multicenter survey on safety and efficacy. Hepatology 2013;57:2448-57.

3. Kashani A, Lipshutz HG, Klein AS, Kim I, Friedman ML, Palomique J, Sundaram V. Embolization of portosystemic shunts for treatment of medically refractory hepatic encephalopathy. Liver Transpl 2016;22:1734-5.

4. An J, Kim KW, Han S, Lee J, Lim YS. Improvement in survival associated with embolisation of spontaneous portosystemic shunt in patients with recurrent hepatic encephalopathy. Aliment Pharmacol Ther 2014;39:1418-26.

5. Naeshiro N, Kakizawa H, Aikata H, Kan H, Fujino H, Fukuhara T, Kobayashi T, Honda Y, Miyaki D, Kawaoka T, Tsuge M, Hiramatsu A, Imamura M, Kawakami Y, 
Hyogo H, Ishikawa M, Awai K, Chayama K. Percutaneous transvenous embolization for portosystemic shunts associated with encephalopathy: Long-term outcomes in 14 patients. Hepatol Res 2014;44:740-9.

6. Zidi SH, Zanditenas D, Gelu-Siméon M, Rangheard AS, Valla DC, Vilgrain V, Pelletier GM. Treatment of chronic portosystemic encephalopathy in cirrhotic patients by embolization of portosystemic shunts. Liver Int 2007;27:1389-93.

7. Kessler J, Trerotola SO. Use of the Amplatzer Vascular Plug for embolization of a large retroperitoneal shunt

Cite this article as: Berthod PE, Chevallier O, Latournerie M, Gehin S, Falvo N, Midulla M, Loffroy R. Atypical use of ALN IVC filters as protection devices prior to embolization of a large portosystemic shunt with Amplatzer Vascular Plugs and Glubran 2 cyanoacrylate glue. Quant Imaging Med Surg 2018;8(4):452-456. doi: 10.21037/qims.2018.03.11 during transjugular intrahepatic portosystemic shunt creation for gastric variceal bleeding. J Vasc Interv Radiol 2006;17:135-40.

8. Boixadera H, Tomasello A, Quiroga S, Cordoba J, Perez M, Segarra A. Successful embolization of a spontaneous mesocaval shunt using the Amplatzer Vascular Plug II. Cardiovasc Intervent Radiol 2010;33:1044-8.

9. Ford JM, Shah H, Stecker MS, Namyslowski J.

Embolization of large gastric varices using vena cava filter and coils. Cardiovasc Intervent Radiol 2004;27:366-9. 